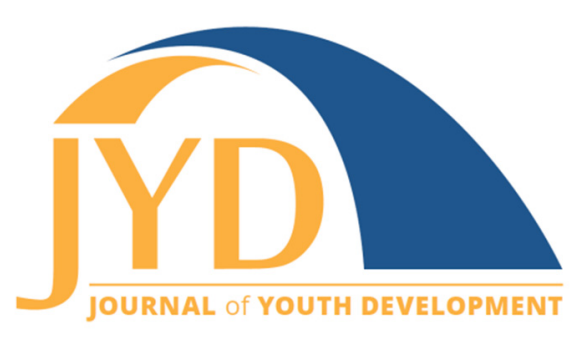

http://jyd.pitt.edu/ | Vol. 13 Issue 1-2 DOI 10.5195/jyd.2018.607 | ISSN 2325-4017 (online)

\title{
Camp Research: What? So What? What's Next?
}

\author{
Karla A. Henderson \\ North Carolina State University \\ karla_henderson@ncsu.edu
}

\begin{abstract}
This special issue of the Journal of Youth Development provides a means to highlight where camp research is today based on the articles presented. Several common areas are identified: role of theory, addressing social issues, methodological imagination, emerging audiences, samples, linking operations and outcomes research, staff and youth development, moving outcomes from what to how, and thoughtful and intentional implications for practice. Areas that need additional consideration in future camp research and issues that can be addressed by camp professionals include further examining how positive change occurs in camp, noting the value of the transfer of camp experiences to later life, using critical analyses of what camp experiences mean, and examining areas that have been under-researched such as day camps.
\end{abstract}

Key words: camp research, youth development, camp outcomes

Camp research is almost 100 years old. Research conducted in 1929 by Dimock and Hendry explored character development in camps. Compilations of information about research in camping have been commonplace since the 1950s with publications such as Annotated Bibliography on Camping by Barbara Ellen Joy (1955). These bibliographies were updated regularly through the 1980s when camp research presentations became a regular part of the annual American Camp Association (ACA) Conferences and have been almost continuous ever since. The turn into the $21^{\text {st }}$ century, however, has seen a resurgence and growth related to camp research and particularly to the documentation of youth development outcomes and the application of research to improved camp practice.

This special issue of the Journal of Youth Development provides a means to assure that emerging camp research finds its way into the research literature and data bases beyond trade

\footnotetext{
(c)) EY New articles in this journal are licensed under a Creative Commons Attribution 4.0 License. This journal is published by the University Library System, University of Pittsburgh and is cosponsored by the University of Pittsburgh Press. The Journal of Youth Development is the official peer-reviewed publication of the National Association of Extension 4-H Agents and the National AfterSchool Association.
} 


\section{Camp Research: What? So What? What's Next?}

journals, student research, and conference proceedings. In this summary article, I highlight briefly how changes have occurred in camp research over the years and how these papers contribute to a rapidly growing body of knowledge about organized camp experiences. I note the similarities among the approaches and findings in some of these papers and what they contribute to a better understanding of camp research and practice as well as where future research can evolve.

\section{Overview of Camp Research: What Was}

In 2007 my colleagues and I (Henderson, Bialeschki, \& James) wrote an overview of camp research. We highlighted the recent research undertaken, particularly by the ACA, and also identified some of the problems with camp research and offered ideas for what future camp research might include. We described two major study areas: operations and outcomes. We also noted that methodological approaches had become more sophisticated but also indicated that there remained constraints going into the future (e.g., sample size, lack of follow-up measures, the narrow scope and standardization of outcome measures, and the challenges of reporting the research and sharing it with practitioners).

We suggested that outcome measures for youth development likely would go through considerable refinement and expansion in future years, and camp researchers would need to remain closely connected to youth development researchers. We also stated that the challenge would be to translate findings into action and to use research to improve practice and demonstrate the relevance of camp experiences. This special issue has addressed a number of past concerns and sets the stage for further research and translating findings to practice.

\section{This Special Issue: What Is}

This special issue of the Journal of Youth Development is moving camp research solidly into the $21^{\text {st }}$ century. It progresses the field forward in a number of ways. As Ozier (2018) noted in his introductory thought piece, camp is more than summer learning; it offers an opportunity to develop life skills to extend into the future. I contend that camp effectively uses peoplecentered recreational elements to promote the potential for lifelong learning as well as the fun and games of camp that foster more immediate developmental opportunities. These papers underline the value that most people agree camp has and take readers unabashedly into the mechanisms that enable significant camp outcomes to occur. 


\section{Camp Research: What? So What? What's Next?}

Several aspects about the approaches and findings from the papers in this special issue are worthy of comment. I was encouraged to see the volume of submissions generated for this special issue. The amount of camp research that is of high enough quality to merit scientific review and publication is heartening. The purpose of a special issue of a journal often is to generate more research about a topic. In the case of this special issue, camp research studies already exist, and it is likely that this journal will be an outlet for future studies about youth development through camp experiences.

As I read the papers included in this special issue, I noted nine areas and trends that make distinct contributions to better understanding camp experiences for youth and adults: role of theory, addressing social issues, methodological imagination, emerging audiences, samples, linking operations and outcomes research, staff and youth development, moving outcomes from what to how, and thoughtful and intentional implications for practice.

\section{Theory}

Theory and conceptual frameworks are the foundations of research. They provide the basis for conceptualizing research studies and the explanation based on findings or facts that can provide a core for future research. Theory gives order and insight into what is, or can be, observed (Henderson, 2006). Most of the studies in this special issue provide a clear theoretical framework for the research. The use of positive youth development (PYD) is evident in several studies (e.g., Olsen, Powell, Garst, \& Bixler, 2018; Rubin, Hagler, Burton, \& Rhodes, 2018; Sendak, Schilstra, Tye, Brotkin, \& Maslow, 2018). PYD contends that youth thrive when their strengths and contextual assets (e.g., relationships with adults, activity opportunities) are aligned. Other theories also contributed to the way research was undertaken for this special issue. For example, Perry's (2018) focus on race evasiveness in camp highlighted the value of using critical race theory. Lacanienta, Ellis, Taggart, Wilder, and Carroll (2018) used the conceptual model of theme to examine how camps might be better marketed. In typical qualitative fashion, Martin (2018) developed a camp-based model of youth development leadership that emerged from the data. This model included community, empowerment, openness, and character.

\section{Social Issues}

The conceptual framework of $21^{\text {st }}$ century skills addresses a social and workforce development approach that defines the competencies and skills young people will need for the future. This 


\section{Camp Research: What? So What? What's Next?}

social framework provided a backdrop for several of the studies in this special issue: college readiness (Whittington \& Garst, 2018), workplace readiness (Wilson \& Sibthorp, 2018), and creativity and applying divergent thinking (Lynch, Hegarty, Tauntvein, N., \& Plucker, 2018). The idea of $21^{\text {st }}$ century learning skills are not necessarily new to camp or youth research, but the conceptual framework provides a way to frame the social contributions of camp. Another example of tackling pressing social issues is the work Perry (2018) did regarding the racism that continues to exist in society as well as potentially in camps.

\section{Methodological Imagination}

The research presented in this special issue also highlights a diversity of methodological approaches. Researchers have moved beyond descriptive survey designs, although these approaches remain useful. The papers here demonstrate examples of literature reviews (e.g., Sendak et al., 2018; Olsen et al., 2018), mixed methods (e.g., Sorenson, 2018; Whittington \& Garst, 2018), qualitative analyses (Baker, 2018; Martin, 2018), archival data (e.g., Bird \& Subramaniam, 2018), and rigorous instrument development (e.g., Bennett, 2018; Gillard, 2018; Lewis et al., 2018). Although Perry (2018) used primarily a qualitative approach, he also introduced his personal experience in teaching and experiencing race evasiveness in camps, almost akin to an autoethnographic approach.

\section{Emerging Audiences}

Camp research sometimes appears to be rather generic with the idea that a camp is a camp is a camp. Yet, as more is learned about camp experiences, different groups clearly have distinctive experiences and some additional specific outcomes. For example, camps with a faith-based focus may have many of the same outcomes as other camps, as Sorenson (2018) found. However, Sorenson found that the emphasis on growth in religious faith resulted in outcomes that were particular and meaningful in Christian camps. Similarly, the study by Manning et al. (2018) examined how peer mentoring might make a difference in adherence to diabetes monitoring among campers as well as staff. In addition, Sendak et al., (2018) uncovered that the outcomes from medical camps have medical implications but can be clearly linked to positive youth development in general. 


\section{Camp Research: What? So What? What's Next?}

\section{Samples}

Related to emerging audiences is also the source of samples for camp research. One of the criticisms of past camp research often has been its focus on single camps, thus limiting the generalizability to other camps. I would argue that a sound theoretical foundation might make generalizing a greater possibility, but a broader sample size and representation is useful in building a body of knowledge. Whittington and Garst (2018) sampled camp alumni in a national study to explore college readiness. Cousineau (2018) used secondary data from the National Canadian Study of camps to look at the short and long-term effects of camp on camper selfconcept. Baker (2018) studied camp counselors' reflections from various camps across Canada and found commonly that they struggled with social isolation, the need to be accepted, and the emotional demands of caring for campers. Although limited to 4-H camps in California, Bird and Subramanium looked at key processes (e.g., youth-adult partnership and opportunities for meaningful contribution) among the camps leading to enhanced experiences. In another California 4-H study (Lewis et al., 2018), an evaluation tool was developed across camps that is being used to provide a common base for further training in California to enhance positive youth development outcomes.

\section{Linking Operations and Outcomes}

My colleagues and I (Henderson et al., 2007) noted that two arbitrary study areas existed historically in camp research. Although that conclusion may remain true to some extent, the studies in this special issue showed how much crossover exists between how a camp operates

and the outcomes of the camp. For example, Lacanienta et al. (2018) focused on using theming to market camps. The theming also related to the outcomes that occurred in camp. Rubin et al. (2018) discussed the outcome of bonds formed at camp, and noted the implications for staff retention. Cousineau (2018) also showed how different outcomes might compound to create greater change that can be facilitated by camp staff. Generally, the studies in this special issue indicated that positive youth development outcomes cannot be meaningful unless they are linked to how a camp operates.

\section{Staff and Youth Development}

Typically when positive youth development is discussed, it is assumed that campers are being highlighted. Although not a new idea, the studies in this special issue emphasized how important human development is for staff. With the concept of emerging adults and the idea that youth may extend into an individual's early 20 s, the importance of staff development was 


\section{Camp Research: What? So What? What's Next?}

evident in several studies. Related to $21^{\text {st }}$ century learning were Martin's (2018) findings of how older youth in Leader-in-Training programs developed leadership that had implications for transference beyond camp. Bird and Subramanium (2018) found that staff had greater developmental outcomes than did the campers when measured using the same scales. Wilson and Sibthorp (2018) also noted the learning transfer perceived by campers that had implications for later in life. Manning et a1. (2018) described the benefits to counselors who had diabetes in addition to changes that occurred in the campers with diabetes with whom they worked.

\section{Moving from What to How}

Much of the research on camp experiences has focused on determining outcomes. For example, ACA's (2005) large national study found that:

- Children become more confident and experience self-esteem.

- Children develop more social skills that help them to make new friends.

- Children grow more independent and show more leadership qualities.

- Children become more adventurous and willing to try new things.

Although describing these findings was important, the conclusions raised new questions about how these outcomes occurred. Several of the studies in this special issue have moved beyond conclusions regarding WHAT to the HOW. Some of these how findings are quite general, but they provide an entrée into what may be next in camp research and practice. For example, Rubin et al. (2018) were interested in not just what bonds formed in a Jewish camp, but wanted to know how they occurred and what role religion might have in understanding how the bonds formed. Perry (2018) gave examples of how he saw racism played out in camp as well as reactions to his staff training. Olsen et al. (2018) conceptualized the relationship between camp and first-year college experiences by identifying some of the commonalities among the physical, social, emotional, and intellectual structuring of camps and campuses. Bird and Subramanium (2018) were also interested in the key processes that occurred that led to enhanced camper experiences. Similarly, Lynch et al. (2018) examined how creative experiences might be facilitated in camp. Wilson and Sibthorp (2018) began to explore the mechanisms that enhanced workplace readiness such as experiential learning, camp as separate time and space, camp schedules, the role of counselors, communal living, safe and supportive environments, and diversity of people. Further, Gillard (2018) investigated the relationship staff encouragement had relative to positive outcomes at a ropes course. 


\section{Camp Research: What? So What? What's Next?}

\section{Thoughtful and Intentional Implications for Practice}

The final and impressive parallel I noted among almost all of these studies was the emphasis on applications and implications for practice. The Journal of Youth Development has a heavy emphasis on practice; camp is certainly a field of practice, and the articles in this special issue were explicit in how the information could be applied. In some cases, the suggestions were common sense, but in other cases they were quite specific to how the findings related to improving the quality of camp experiences. These implications figure heavily into discussing the So What? of this special issue.

\section{Camp Research. So What?}

One of the criticisms of research in general is the question of what theories, statistics, and findings mean. What difference does the research make in terms of developing the body of knowledge and perhaps more specifically for how to apply the information to make camp experiences better? As noted above, a number of good examples exist in this special issue. Perhaps unequivocally, research has shown that camps can make a positive difference in the lives of children and adults. The transference of skills from camp to everyday living and to future work and leisure life has been shown to a growing extent. These studies have also laid a groundwork for going further in depth with understanding more about camp experiences in certain contexts (e.g., faith-based communities, for people with disabilities, for young people in leadership positions) and addressing what is special about camp that facilitates human development.

Of note is the way these studies can challenge readers to assess and re-evaluate some of the assumptions made about camp. Camp is not always inherently good. For example, although many people believe camp is a safe place free of sexism or racism, Lynch et al. (2018) pointed out the need to help boys focus on creativity just as much as girls, and Perry (2018) noted how White privilege continues to occur in camps just as it does in society at large. Baker (2018) also showed in her article on liminality and communitas that being a camp counselor can be a positive experience, but is not without struggles that must be acknowledged by camp directors. Similarly, Rubin et al. (2018) discussed the paradoxes (e.g., relating to campers while also exerting authority) associated with working in a Jewish camp. 


\section{Camp Research: What? So What? What's Next?}

\section{Camp Research. What's Next?}

The development of a body of knowledge is a continuous process. As more is learned, more sophisticated questions arise. When I look back at some of the research I did early in my career during the 1980s, it seems so elementary compared to what many of the erudite studies in this special issue portray. However, without earlier research the foundations for the refined questions and methods used today would not exist.

I sometimes wonder if camp researchers have answered many of the easy questions about camp experiences. Describing what is often is easier than describing how. Although researchers would like to find the definitive answers, social science is continually evolving and knowledge continues to be built as society changes. Human behavior and change are complicated, and the processes for understanding change are complex. Therefore, camp professionals need to continue to keep asking the hard questions and using the current theory and findings to build on future research and practice. In my opinion, the studies in this special issue point to four conclusions that can guide research and practice into the next few years.

1. Camp experience can make a difference in people's lives. Researchers have come to this conclusion in multiple ways. However, as noted above, how those experiences come about must continue to be considered. The combination of outcomes and operations, including the processes that occur at camp, may be similar to or quite different from school or other youth organizations. Camp researchers need to further examine how change occurs and what is distinctive about camp experiences. There is a need to emphasize the role of critical incidents, turning points (Olsen et al., 2018)), and active ingredients (Rubin et al., 2018) as suggested in this special issue.

2. An idea that was reinforced in these studies is the way that camp provides a transition to or transfer of skills to daily living and to future lifelong learning. Going to college may not be the goal for all young people, but all will have to live in the society and be family members and community citizens. The role that camp plays in the broader process of life beyond the immediate outcomes at camp must be the essence of research and practice for the future. The educational and recreational aspects of camp are central to future learning and living for youth and adults.

3. Almost everyone believes that camp experiences are good for people. That assumption is true for many people, but if the research and practice are to grow and improve, camp 


\section{Camp Research: What? So What? What's Next?}

researchers as well as other camp staff must recognize that there can be a difficult or even dark side to camp experiences. Therefore, the application of critical theory and an acknowledgement that liminality may exist is essential. Camp can be a microcosm of society with its goodness and badness. Therefore, acknowledging issues such as racism, sexism, and other paradoxes in camp should be acknowledged so they can be addressed head on.

4. Finally, important questions have been tackled in this special issue. However, there remain areas that are not addressed. For example, little research has occurred about day camps. This experience can be similar or quite difference from resident camps and much more research about the processes and mechanism that can create positive growth beyond the day care or recreation benefits of day camps. Another area that is missing related to critical theory is to explore why some people, both children and adults, have negative experiences at camp such that they never return. We can learn a great deal from those deleterious experiences as well as the positive ones.

In summary, the studies in this special issue provide a barometer for where camp research related to youth development is in 2018. I would expect to see many more studies in the future that use theoretical and conceptual foundations to explore the complex questions related to how camp experiences contribute to human development. Further, the ways that camps provide a foundation for future academic, recreational, family, and community skills must remain at the forefront of investigations.

\section{References}

American Camp Association. (2005). Youth development outcomes of the camp experience: Directions. Retrieved from: http://www.acacamps.org/research/ydo.php.

Baker, M. (2018). Welcome to the bubble: Experiences of liminality and communitas among summer camp counsellors. Journal of Youth Development, 13(1-2), 24-43. doi: $10.5195 / \mathrm{jyd} / 2018.565$

Bennett, T. (2018). Including the youth perspective: The development of the CPQA camper survey. Journal of Youth Development, 13(1-2), 266-285. doi:10.5195/jyd.2018.559

Bird, M., \& Subramaniam, A. (2018). Teen staff perceptions of their development in camp: Insights for theory and practice. Journal of Youth Development, 13(1-2), 62-82. doi:10.5195/jyd.2018.568 


\section{Camp Research: What? So What? What's Next?}

Cousineau, L. S. (2018). Camper self-concept promotes environmental awareness: A relationship mediated by social inclusion. Journal of Youth Development, 13(1-2), 144160. doi:10.5195/jyd.2018.526

Dimock, H. S., \& Hendry C. E. (1929). Camping and character: A camp experiment in character education. New York: Association Press.

Gillard, A. (2018). Staff engagement and camper outcomes at a low ropes course. Journal of Youth Development, 13(1-2), 240-249. doi:10.5195/jyd.2018.493

Henderson, K. A., Bialeschki, M. D., \& James, P.A. (2007). Overview of camp research. Child and Adolescent Psychiatric Clinics of North America, 16, 755-767.

Henderson, K. A. (2006). Dimensions of choice: Qualitative approaches to research in parks. Recreation, tourism, sport, and leisure. State College, PA: Venture Publishing.

Joy, B. E. (1955). Annotated bibliography on camping. Martinsville (IN): American Camping Association.

Lacanienta, A., Ellis, G., Taggart, A., Wilder, J., \& Caroll, M. Does theming camp experiences lead to greater quality, satisfaction, and promotion? Journal of Youth Development, 13(1-2), 216-239. doi:10.5195/jyd.2018.535

Lewis, K. M., Bird, M., Wilkins, T., Borba, J., Nathaniel, K., \& Schoenfelder, E. (2018). Developing a common evaluation tool for camps. Journal of Youth Development, 13(12), 306-315. doi:10.5195/jyd.2018.539

Lynch, M. L., Hegarty, C. B., Trauntvein, N., \& Plucker, J. (2018). Summer camp as a force for $21^{\text {st }}$ century learning: Exploring divergent thinking and activity selection in a residential camp setting. Journal of Youth Development, 13(1-2), 286-305. doi:10.5195/jyd.2018.544

Manning, A. S., Pollock, M., Clements, B., Furutani, E., Brotkin, S., Mansfield, J., . . Maslow, G. (2018). Young adult counselors with diabetes at diabetes camps: The effect of being a peer mentor on counselors' health behavior. Journal of Youth Development, 13(1-2), 250-265. doi:10.5195/jyd.2018.540

Martin, K. (2018). Summer camp youth leadership development: An investigation of adolescents' perceptions of best practices. Journal of Youth Development, 13(1-2), 161182. doi:10.5195/jyd.2018.536

Olsen, L., Powell, G.M., Garst, B.A., \& Bixler, R.D. (2018). Camp and college parallels: Crucibles for transition-linked turning-points. Journal of Youth Development, 13(1-2), 126-143. doi: $10.5195 /$ jyd.2018.558

Ozier, L. W. (2018). Learning landscapes: The educational spectrum from camps to classrooms. Journal of Youth Development, 13(1-2), 4-13. doi:10.5195/jyd.2018.612 


\section{Camp Research: What? So What? What's Next?}

Perry, S. C. (2018). Race-evasiveness among camp staff. Journal of Youth Development, 13(12), 14-23. doi:10.5195/jyd.2018.555

Rubin, R.O., Hagler, M., Burton, S.A., \& Rhodes, J.E. Striking a balance: An exploration of staffcamper relationship formation. Journal of Youth Development, 13(1-2), 44-61. doi:10.5195/jyd.2018.537

Sendak, M. D., Schilstra, C., Tye, E., Brotkin, S., \& Maslow, G. (2018). Positive youth development at camps for youth with chronic illness: A systematic review of the literature. Journal of Youth Development, 13(1-2), 201-215. doi:10.5195/jyd.2018.551

Sorenson, J. (2018). The fundamental characteristics and unique outcomes of Christian summer camp experiences. Journal of Youth Development, 13(1-2), 183-200. doi:10.5195/jyd.2018.556

Whittington, A. \& Garst, B. (2018). The role of camp in shaping college readiness and building a pathway to the future for camp alumni. Journal of Youth Development, 13(1-2), 105125. doi:10.5195/jyd.2018.519

Wilson, C., \& Sibthorp, J. (2018). Examining the role of summer camps in developing academic and workplace readiness. Journal of Youth Development, 13(1-2), 83-104.

doi:10.5195/jyd.2018.563 